Conclusion: We report a rare case of synovial metastasis concomitant to a lung adenocarcinoma. It is important to make a rapid diagnosis as early recognition of malignant infiltration into joints ensure appropriate multidisciplinary management decisions. Disclosure of Interests: None declared DOI: 10.1136/annrheumdis-2021-eular.2143

\section{AB0771 $\quad$ HIGH DOSE INTRAVENOUS METHYLPREDNISOLONE INDUCES RAPID IMPROVEMENT OF VISUAL ACUITY IN NON-INFECTIOUS UVEITIS OF DIFFERENT IMMUNE MEDIATED INFLAMMATORY DISEASES}

N. Vegas-Revenga ${ }^{1}$, J. L. Martín-Varillas ${ }^{2}$, V. Calvo-Río ${ }^{3}$, I. González-Mazón ${ }^{3}$, L. Sanchez-Bilbao ${ }^{3}$, E. Beltrán ${ }^{4}$, A. Fonollosa ${ }^{5}$, O. Maiz-Alonso ${ }^{6}$, A. Blanco ${ }^{7}$, M. Cordero-Coma ${ }^{8}$, N. Ortego ${ }^{9}$, I. Torre-Salaberri ${ }^{10}$, F. Francisco ${ }^{11}$, S. Muñoz Fernandez $^{12}$, M. D. M. Esteban-Ortega ${ }^{13}$, M. Díaz-Llopis ${ }^{14}$, J. Cañal' ${ }^{15}, \mathrm{~J}$. A. Ventosa ${ }^{15}$, R. Demetrio-Pablo ${ }^{15}$, L. Domínguez ${ }^{16}$, M. Agudo-Bilbao ${ }^{3}$, S. Castañeda ${ }^{17}$, I. Ferraz-Amaro ${ }^{18}$, M. A. González-Gay ${ }^{3}$, R. Blanco ${ }^{3}$. ${ }^{1}$ Hospital Galdakao-Usansolo, Rheumatology, Galdakao, Spain; ${ }^{2}$ Hospital de Sierrallana, Rheumatology, Torrelavega, Spain; ${ }^{3}$ Hospital Universitario Marqués de Valdecilla, Rheumatology, Santander, Spain; ${ }^{4}$ Hospital Universitario Doctor Peset, Rheumatology, Valencia, Spain; ${ }^{5}$ Hospital Universitario de Cruces, Ophthalmology, Barakaldo, Spain; ${ }^{6}$ Hospital Universitario Donostia, Rheumatology, San Sebastian, Spain; ${ }^{7}$ Hospital Universitario Donostia, Ophthalmology, San Sebastian, Spain; ${ }^{8}$ Hospital de León, Ophthalmology, León, Spain; ${ }^{9}$ Hospital Universitario San Cecilio, Ophthalmology, Granada, Spain; ${ }^{10}$ Hospital Universitario de Basurto, Rheumatology, Bilbao, Spain; ${ }^{11} \mathrm{Hospital}$ Universitario de Gran Canaria Doctor Negrín, Rheumatology, Gran Canaria, Spain; ${ }^{12}$ Hospital Universitario Infanta Sofia, Rheumatology, Madrid, Spain; ${ }^{13} \mathrm{Hospital}$ Universitario Infanta Sofia, Ophthalmology, Madrid, Spain; ${ }^{14} \mathrm{Hospital}$ Universitario La Fe, Ophthalmology, Valencia, Spain; ${ }^{15}$ Hospital Universitario Marqués de Valdecilla, Ophthalmology, Santander, Spain; ${ }^{16} \mathrm{Hospital}$ Universitario San Agustín, Rheumatology, Avilés, Spain; ${ }^{17}$ Hospital Universitario de la Princesa, Rheumatology, Madrid, Spain; ${ }^{18} \mathrm{Hospital}$ Universitario de Canarias, Rheumatology, Canarias, Spain

Background: Rapid and effective remission-inducing therapy is mandatory in uveitis to avoid irreversible structural and functional damage. In some severe cases biological agents might be required (1-6).

High-dose intravenous methylprednisolone (IVMP) may achieve prompt control of inflammation in most immune mediated inflammatory diseases (IMID), including non-infectious uveitis (NIU).

Objectives: To evaluate the efficacy and safety of IVMP pulse therapy in NIU of different IMID.

Methods: Multicentre study of 71 patients with severe uveitis who received IVMP. The underlying diseases were: Vogt Koyanagy Harada disease (VKHD) $(n=24)$, Behçet disease (BD) (19), Sarcoidosis (5) and idiopathic NIU (23). The main outcome variable was Best-Corrected Visual Acuity (BCVA) estimated using the Snellen chart. BCVA that was assessed at 0 (basal), 2-5, 7, 15 and 30 days after IVMP.

The results are expressed as mean $\pm S D$ in normally distributed variables, or as median [IQR] when are not. Comparison of continuous variables was performed using the Wilcoxon test.

Results: We studied 46 $/ 25$ patients. The main features are shown in Table 1. IVMP dose ranged from 250 to $1000 \mathrm{mg} /$ day administered for 3-5 consecutive days, the dose was established according to the presence or not of other systemic manifestations apart from uveitis. All of them had active intraocular inflammation at the moment of the study. BCVA values improved considerably after 1 month (Figure 1). No major side effects were observed.

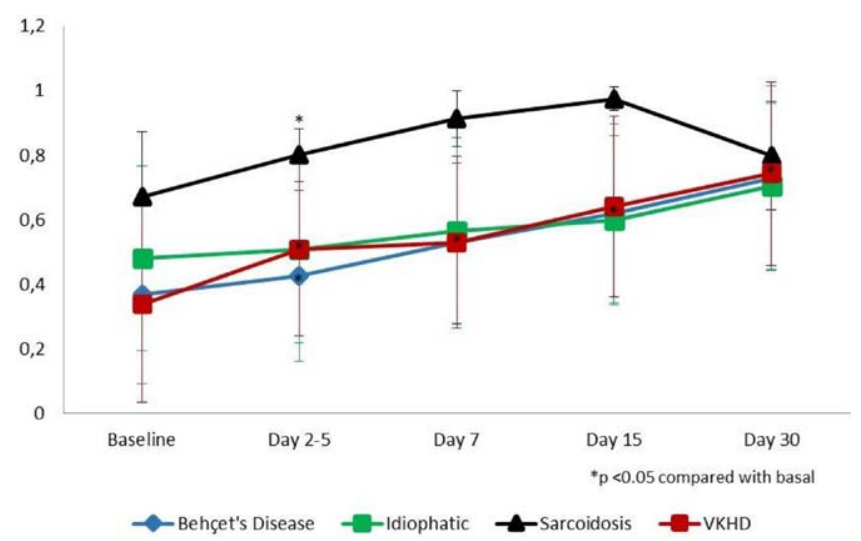

Figure 1. Improvement of best corrected visual acuity (BCVA).
Conclusion: High-dose IVMP pulse therapy is useful and safe for a prompt control of BCVA regardless of the underlying IMID.

\section{REFERENCES:}

[1] Vegas-Revenga N, et al. Am J Ophthalmol. 2019; 200:85-94. doi: 10.1016/j. ajo.2018.12.019

[2] Calvo-Río V, et al. Clin Exp Rheumatol. 2014;32(4 Suppl 84): S54-7. PMID: 25005576

[3] Santos-Gómez M, et al. Clin Exp Rheumatol. 2016;34(6 Suppl 102): S34S40. PMID:27054359

[4] Atienza-Mateo B, et al. Rheumatology (Oxford) 2018;57(5):856-864. doi: 10.1093/rheumatology/kex480.

[5] Atienza-Mateo B, et al. Arthritis Rheumatol. 2019; 71(12):2081-2089. doi 10.1002/art.41026.

[6] Martín-Varillas JL, et al. Ophthalmology. 2018;125(9):1444-1451. doi 10.1016/j.ophtha.2018.02.020

Table 1. Main features of 71 patients with NIU. Data are of affected eyes.

\begin{tabular}{|c|c|c|c|c|c|}
\hline & VKHD & Idiophatic & Behcet's & Sarcoidosis & s Overall \\
\hline & $(n=24)$ & $(n=23)$ & $(n=19)$ & $(n=5)$ & $(n=71)$ \\
\hline Men/Women, $\mathrm{n}$ & $5 / 19$ & $9 / 14$ & $9 / 10$ & $2 / 3$ & 71 \\
\hline Mean age (years) $\pm \mathrm{SD}$ & $42 \pm 11$ & $47 \pm 15$ & $33 \pm 10$ & $42 \pm 22$ & - \\
\hline $\begin{array}{l}\text { Unilateral/Bilateral } \\
\text { NIU, n (\%) }\end{array}$ & $2(8.3) / 22(91.7)$ & $10(43.5) / 13(56.5)$ & $4(21) / 15(79)$ & $3(60) / 2(40)$ & $19 / 52$ \\
\hline \multicolumn{6}{|l|}{ NIU patterns, n (\%) } \\
\hline Posterior uveitis & $6(25)$ & $9(39.1)$ & $3(15.8)$ & $1(20)$ & 19 \\
\hline Panuveitis & $18(75)$ & $14(60.9)$ & $16(84.2)$ & $4(80)$ & 52 \\
\hline \multicolumn{6}{|c|}{ Laboratory data, $\mathrm{n}(\%)$} \\
\hline ANA & $2(8.34)$ & $2(8.7)$ & $0(0)$ & $1(20)$ & 5 \\
\hline HLA B27 & $0(0)$ & $4(17.4)$ & $0(0)$ & $0(0)$ & 4 \\
\hline HLA B29 & $0(0)$ & $1(4.3)$ & $0(0)$ & $0(0)$ & 1 \\
\hline HLA B51 & $0(0)$ & $5(21.7)$ & $8(42)$ & $3(60)$ & 16 \\
\hline Angiotensin & $1(4.17)$ & $2(8.7)$ & $0(0)$ & $1(20)$ & 4 \\
\hline $\begin{array}{l}\text { Converting Enzyme } \\
\text { (ACE) }\end{array}$ & & & & & \\
\hline
\end{tabular}

Disclosure of Interests: None declared

DOI: 10.1136/annrheumdis-2021-eular.2159

\section{AB0772 $\quad$ JAK INHIBITORS IN REFRACTORY ADULT AND CHILDHOOD ONSET STILL'S DISEASE}

L. Gillard ${ }^{1}$, S. Mitrovic ${ }^{1,2}$, H. Reumaux ${ }^{3}$, M. Michaud ${ }^{4}$, F. Cohen ${ }^{1,2}$, J. Pouchot $^{5}$

B. Fautrel ${ }^{1,2,6}$. ${ }^{1}$ Pitié-Salpêtrière, AP-HP, Rheumatology Department, Paris,

France; ${ }^{2}$ Sorbonne Université, Rheumatology Department, Paris, France;

${ }^{3}$ Jeanne de Flandre Hospital, Rheumatology, Lille, France; ${ }^{4}$ Hospital Joseph

Ducuing, Medecine Interne, Toulouse, France; ${ }^{5}$ European Hospital Georges

Pompidou, Medecine Interne, Paris, France: ${ }^{6}$ Pierre Louis Institute of

Epidemiology and Public Health, INSERM UMR 1136, Paris, France

Background: Excessive and inappropriate production of pro-inflammatory cytokines such as interleukin (IL)-1, IL-6 or IL-18, is a pathogenic cornerstone in adult and childhood onset Still's disease. Beyond therapies targeting IL-1 or IL-6, Janus kinases (JAK) inhibitors have been proposed for adult-onset Still's disease (AOSD) patients refractory to or intolerant of treatment with biologicals. Recently, it has been suggested that JAK inhibitors might be efficient in refractory AOSD patients ${ }^{1}$.

Objectives: To assess the efficacy and safety of JAK inhibitors in the treatment of refractory systemic juvenile idiopathic arthritis (SJIA) or AOSD.

Methods: This retrospective study was based on a national survey of the departments of rheumatology, paediatric rheumatology and internal medicine in al French hospitals from an online call of the "Club Rhumatismes et Inflammation" (www.cri-net.com). The data were collected using a standardized questionnaire, and analyzed at different time points (treatment initiation, M1, M3, M6 and end of the follow-up). The response to JAK inhibitors was categorized as: complete remission (resolution of all clinical and biologic signs), partial remission (clinical improvement with persistence of a few symptoms) or failure (lack of clinical or biological improvement).

Results: 6 patients ( 5 adults and 1 child) were recruited (Table 1 ). Mean age at treatment start was 39.6 years for the AOSD patient and 6 years for the SJIA patient, and mean disease duration was 5.3 years. The clinical expression was predominantly systemic in 5 five patients and chronic articular in one. Response to corticosteroids, conventional synthetic or biological Disease Modifying Anti-Rheumatic Drugs had been considered inadequate in all patients. Baricitinib was used in 3 patients, ruxolitinib in 2 , and tofacitinib in 1. Steroids were concurrently used in all patients, anakinra in one, methotrexate and anakinra in one. At a mean (SD) follow-up of 9.5 months, partia response was observed in $4(66.7 \%)$ cases (patients with ruxolitinib, tofacitinib 